\title{
THE ROLE OF NATURAL KILLER CELLS IN THE DEVELOPMENT OF HERPES SIMPLEX VIRUS TYPE 1 INDUCED STROMAL KERATITIS IN MICE
}

\author{
RICHARD R. TAMESIS, ELISABETH M. MESSMER, BEVERLY A. RICE, JAMES E. DUTT and \\ C. STEPHEN FOSTER
}

Boston, Massachusetts

\begin{abstract}
SUMMARY
Natural killer (NK) cells and acquired cell-mediated immunity effector cells (delayed type hypersensitivity (DTH) and cytotoxic T lymphocytes (CTL)) have been reported to play a vital role in the defence of the host against tumour and viral infections in locations other than the eye. A vigorous cellular inflammatory response to viral infections of the cornea, however, with the attendant damage to the corneal clarity, has obvious evolutionary disadvantages, and a substantial body of evidence indicates that in animals (e.g. mice) which are highly suceptible to inflammatory destruction of the cornea following corneal encounter with herpes simplex virus, it is the animal's immunological/inflammatory response which is responsible for the corneal damage. We examined the role of natural killer cells in the development of herpes stromal keratitis (HSK) in NK-deficient (C57BL/6J-bgi (beige)) mice and their NK-competent (C57BL/6J (black)) relatives. The beige (NK-deficient) mice were just as resistant to HSK as were the black mice. We also studied the effects of $N K$ cell depletion of $B A L B / c$ Igh-1 disparate congenic mice. C.AL-20 $\left(\right.$ Igh- $\left.1^{\mathrm{d}}\right)$ mice are ordinarily highly susceptible to necrotising HSK. In vivo NK-cell depletion in these mice significantly decreased the incidence and severity of HSK in these animals $(p<0.0005)$. Corneas from untreated C.AL-20 mice contained $T$ cells, macrophages and NK cells. The corneal infiltrate from NK-depleted C.AL-20 mice consisted of T cells and macrophages but no NK cells. These data indicate that NK cells are participants in the development of HSK in the murine model of this disease.
\end{abstract}

We have previously shown that susceptibility to herpes simplex virus type 1 (HSV-1) induced stromal keratitis (HSK) in the mouse is influenced by the Igh-1 or closely linked loci on chromosome 12. 1.2 Following intracorneal

From: Hilles Immunology Laboratory, Massachusetts Eye and Ear Infirmary, Harvard Medical School, Boston, Massachusetts. USA.

Correspondence to: C. Stephen Foster, MD. Massachusetts Eye and Ear Infirmary, 243 Charles Street, Boston, MA 02114. USA. inoculation with HSV-1 strain KOS, A/J (Igh- ${ }^{e}$ ) and C.AL-20 (Igh- $\left.I^{d}\right)$ mice develop severe stromal keratitis. In contrast, C.B-17 (Igh-1 ${ }^{\text {b) }}$ mice, which are genetically identical to C.AL-20 mice except for a limited area on chromosome 12 at the Igh-1 region, are resistant to the development of the destructive inflammatory keratopathy.

Histologically, corneas of HSK-susceptible C.AL-20 mice show large numbers of neutrophils and macrophages on day 21 post-inoculation, whereas these cells are absent from corneas of resistant C.B-17 mice. T helper delayed type hypersensitivity (DTH) to $\mathrm{T}$ suppressor/cytotoxic cell ratios are significantly higher in susceptible C.AL-20 mice (7:1), indicating a role for $\mathrm{T}$ helper cell mediated recruitment of these cell populations. Relatively high numbers of $\mathrm{T}$ suppressor/cytotoxic cells ( $\mathrm{T}$ helper/T suppressor ratio $1: 8$ ) are found in corneas of resistant C.B-17 mice, suggesting a role for the Ts/c cell subset in mediating protection from HSK. ${ }^{3}$ Natural killer (NK) cell cytotoxicity against herpes simplex virus infected cells is significantly higher in C.AL-20 splenocytes compared with splenocytes from resistant C.B-17 mice 24 hours after intraperitoneal infection. ${ }^{+}$In vitro blastogenic transformation and proliferation of splenocytes in response to HSV exposure differs among the BALB/c congenics, with susceptible C.AL-20 mice exhibiting the highest response, indicating a hyper-responsiveness to HSV-1 compared with resistant C.B-17 mice. Herpes-specific cytotoxic $\mathrm{T}$ cell activity of spleen and peripheral lymph nodes is different between the C.AL-20 and C.B-17 strains, with high cytotoxic T lymphocyte (CTL) activity not correlating with high susceptibility to keratitis. ${ }^{5}$ Significant HSV-specific suppression of delayed hypersensitivity response is present in each of the congenics after simultaneous subcutaneous and corneal priming. AntiHSV-1 antibody activity is similar in the susceptible C.AL-20 and resistant C.B-17 mice; however, IgGl and $\mathrm{IgG} 2 \mathrm{~b}$ are produced earlier after corneal inoculation with HSV- 1 in resistant C.B- 17 mice (unpublished data).

Eye (1994) 8, 298-306 C 1994 Royal College of Ophthalmologists 
Clearly the story is complex and the cellular and molecular details explaining why C.AL-20 mice are highly susceptible and C.B-17 mice are highly resistant are yet to be clarified. The evolution of adaptive immune/inflammatory responses to antigens encountered in the eye has resulted in the development of ocular immune responses which are in some ways different from those which one might expect given, for example, the responses to the same antigen encountered in the skin. ${ }^{68} \mathrm{NK}$ cells are important in the initial extraocular defence against virus infections. ${ }^{9-14}$ Genetically high NK cell activity in mice has been correlated with resistance to lethal HSV-1 infections. ${ }^{12} \mathrm{C} 57 \mathrm{BL} / 6 \mathrm{~J}$ mice carrying the beige mutation $\left(\mathrm{bg}^{\prime} /\right.$ $b g^{j}$ ) have severely impaired NK cell responses and decreased resistance to viral infections. ${ }^{9.15}$ But in view of our earlier observations, we wondered whether high NK activity might be associated, at least in C.AL-20 mice. with increased corneal inflammation in response to HSV corneal inoculation; or on the contrary, whether NK activity could account for some of the protection from HSK enjoyed by C57BL and by C.B-17 mice.

We therefore examined the role of NK cells in HSK by trying to determine whether the development of HSK following corneal challenge with HSV-1 in mice could be influenced by the beige mutation (associated with NK deficiency) in C57BL/6J mice or by in vivo depletion of NK cells with antibody to a glycosphingolipid, ganglio-ntetraosylceramide (asialo GM1), found predominantly on murine NK cells.

\section{MATERIALS AND METHODS}

\section{Experimental Design}

Corneal inoculation and scoring for HSK have been described previously. ${ }^{2}$ Briefly, mice were anaesthetised with pentobarbital, and the right cornea of each mouse was scratched with a gauge 25 needle. Each eye was inoculated with $2 \times 10^{4}$ plaque forming units (PFU) of virus. Animals were scored in a masked fashion three times a week for 21 days after inoculation. Stromal keratitis was graded on a scale of 0 to $4+$. Mice were killed on post-inoculation days (PID) $6,11,15$ and 21 , and the eyes removed for histopathological analysis. Enucleated eyes were snap-frozen with liquid nitrogen and embedded in O.C.T. Compound (Tissue-Tek, Miles Diagnostics Division, Elkhart, IN). Spleens were harvested at the end of the experiments for cytotoxicity assays.

\section{Animals}

C57BL/6J (Igh-1 $\left.{ }^{\mathrm{b}}\right), \mathrm{C} 57 \mathrm{BL} / 6 \mathrm{~J}-\mathrm{bg}^{\mathrm{j}}$ (beige), BALB/cbyJ (Igh- $\left.1^{\mathrm{a}}\right)$, C.AL-20 (Igh- ${ }^{\mathrm{d}}$ ) and C.B-17 (Igh- $\left.1^{\mathrm{b}}\right)$ mice, aged 6-8 weeks, were obtained from Jackson Laboratories (Bar Harbor, ME) and housed in microisolators in our animal facility. All studies conformed with the Helsinki Declaration, The Guiding Principles in the Care and Use of Animals (DHEW Publication, NIH 80-23), and the ARVO resolution on the care of laboratory animals.

\section{Virus}

HSV type 1 KOS strain. obtained from Dr Priscilla
Schaeffer (Harvard Medical School, Boston, MA), was grown and titred on Vero cell monolayers (American Type Culture Collection, CCL 81, Rockville, MD) in our laboratory.

\section{NK Depletion}

Rabbit anti-asialo GMl antibody was obtained from Wako Chemicals, Dallas. TX. On the day of corneal inoculation with HSV-I, mice were injected intraperitoneally with $40 \mu \mathrm{l}$ of antibody. Antibody injections were repeated on days $4,8,12$ and 16 after corneal inoculation.

\section{Target Cell Lines for NK Assay and/or CTL Cytotoxicity Assay}

YAC-1 cells (American Type Culture Collection, TIB 160), an A/Sn T lymphoma cell line used in NK cytotoxicity assays, were grown in RPMI 1640 supplemented with $10 \%$ heat-inactivated fetal calf serum (FCS) and antibiotics $(100 \mathrm{U} / \mathrm{ml}$ penicillin, $100 \mathrm{mg} / \mathrm{ml}$ streptomycin and $250 \mathrm{mg} / \mathrm{ml}$ amphotericin B) as cell suspensions in upright $25 \mathrm{~cm}^{2}$ polystyrene tissue culture flasks (Falcon; Becton Dickinson, Lincoln Park, NJ).

BALB/c 3 T3 clone A31 fibroblasts (American Type Culture Collection. CCL 163), a cell line which we used for CTL cytotoxicity assays, were grown in Dulbecco's modified Eagle's medium supplemented with $10 \%$ heatinactivated FCS and antibiotics in $175 \mathrm{~cm}^{2}$ polystyrene tissue culture flasks (Falcon; Becton Dickinson, Lincoln Park. NJ) as adherent cell cultures at $37^{\circ} \mathrm{C}$ in $5 \% \mathrm{CO}_{2}$.

\section{Effector Cells for NK Assay and for CTL Cytotoricity Assay}

Mice were killed by cervical dislocation. Effector cells from mouse spleens were prepared by teasing spleens apart between two frosted glass slides and depleted of red and dead cells by Lympholyte-M (Cedarlane, Hornby, Ontario) separation as previously described. ${ }^{+}$Lymphocytes were diluted to $4 \times 10^{7}$ cells $/ \mathrm{ml}$ in RPMI 1640 containing $10 \%$ FCS, penicillin (100 units/ml), streptomycin $(100 \mathrm{~m} / \mathrm{ml}$ ) and $10 \mathrm{mM}$ HEPES. Effector cells for the NK assay were obtained from splenocytes depleted of adherent cells and depleted of T cells (effluent from a column with bound anti-Thy 1.2 antibody).

\section{Generation of Cytotoric T Cells}

Cytotoxic $\mathrm{T}$ cells were generated from a modification of techniques described previously. ${ }^{16.17}$ In brief, stimulator cells were prepared by irradiating spleen cells from uninfected syngeneic mice with 2500 rads using a ${ }^{60} \mathrm{Co}$ source and infecting them with HSV-1 (KOS) at a multiplicity of infection (MOI) of $5 \mathrm{PFU}$ per cell for 2 hours at $37^{\circ} \mathrm{C}$ in $5 \%$ $\mathrm{CO}_{2}$. Infected stimulator cells were washed three times prior to culture. For mixed lymphocyte cultures (MLC), $2.5 \times 10^{8}$ spleen cell effectors harvested from the effluent from a $\mathrm{T}$ cell enrichment column (Biotex Laboratories, Edmonton, Alberta, Canada) from HSV-1 (KOS) infected mice were co-cultured with HSV-1 infected $5 \times 10^{6}$ stim- 
ulator spleen cells and $5 \times 10^{8} \mathrm{PFU}$ of heat-inactivated HSV-1 (KOS) in $75 \mathrm{~cm}^{2}$ polystyrene tissue culture flasks (Falcon; Becton Dickinson, Lincoln Park, NJ). The flasks were incubated upright for 4 days at $37^{\circ} \mathrm{C}$ in $5 \% \mathrm{CO}_{2}$.

\section{Cytotoxicity Assays}

$\mathrm{HSV}-1$ infected BALB/c $3 \mathrm{~T} 3$ target cell suspensions were prepared by incubating trypsinised $\mathrm{BALB} / \mathrm{c} 3 \mathrm{~T} 3$ fibroblasts with HSV-1 $(\mathrm{KOS})(\mathrm{MOI}=2)$ for 2 hours at $37^{\circ} \mathrm{C}$ in $5 \% \mathrm{CO}_{2}$. YAC-1 lymphoma cells and infected and uninfected BÁLB/c 3T3 target cells were labelled with 200 $\mathrm{mCi}$ of ${ }^{51} \mathrm{Cr}$ (as $\mathrm{NaCrO}_{4}$; New England Nuclear, Boston, $\mathrm{MA})$. Target cells were washed three times and diluted to $4 \times 10^{5}$ cells $/ \mathrm{ml}$.

Effector cells were harvested and washed twice in Hanks Balanced Salt Solution before resuspending to $2 \times 10^{7}$ cells $/ \mathrm{ml}$ in culture medium. Titrated numbers of effector cells and $2 \times 10^{4}$ target cells were mixed in 96well flat-bottomed microtitre plates (Falcon; Becton Dickinson, Lincoln Park, NJ) at effector-to-target cell ratios of 100,50 and 25 . Target cells also were mixed with medium alone (for spontaneous release), or 5\% Triton X-100 (Sigma, St Louis, MO) alone (for total release). Samples were plated in six replicates. After incubating at $37^{\circ} \mathrm{C}$ in $5 \% \mathrm{CO}_{2}$ (12 hours for YAC-1 cell targets, 18 hours for $\mathrm{BALB} / \mathrm{c} 3 \mathrm{~T} 3$ cell targets), $100 \mathrm{ml}$ of supernatant was harvested from each well, and radioactivity was counted in an LKB-Wallac 1272 gamma counter (LKB instruments, Gaithersburg, MD). Total release was determined by adding $100 \mathrm{ml}$ of $5 \%$ Triton X-100 (Sigma). Spontaneous release was determined by incubating targets with medium only and was less than $30 \%$ of total release. Specific release was calculated as

$$
\begin{aligned}
& \% \text { specific release }= \\
& \frac{(\text { experimental } \mathrm{cpm}-\text { spontaneous } \mathrm{cpm}) \times 100}{\text { total } \mathrm{cpm}-\text { spontaneous } \mathrm{cpm}}
\end{aligned}
$$

Results shown depict the mean of the percentage of cytotoxicity at one E:T ratio $(50: 1)$ for three experiments \pm standard error of the mean (SEM) of experiments.

\section{Immunopathology}

An immunoperoxidase technique was employed to characterise the cell subpopulations in HSV-infected corneas as previously described. ${ }^{2}$ Briefly, $4 \mu \mathrm{m}$ cryostat sections were air dried, fixed for 10 minutes in acetone then incubated for 45 minutes with primary antibodies. Primary antibodies consisted of the following reagents: anti-Thy 1.2 (pan-T, 1:200 dilution) (Becton Dickinson, Mountain View, CA), anti-Mac-1 (macrophages and neutrophils, 1:25 dilution) (Hybritech, San Diego, CA), antimurine Ia (1:100 dilution) (Hybritech), anti-L3T4 (helper/ inducer $\mathrm{T}$ cells, 1:100 dilution) (Becton-Dickinson, Mountain View, CA), Lyt-2 (cytotoxic/suppressor T cells, 1:10 dilution) (Becton Dickinson, Mountain View, CA), and anti-asialo GM1 (NK cells, 1:100 dilution) (Wako Chemicals). Following a blocking for endogenous peroxidase using $0.3 \%$ hydrogen peroxide in phosphate-buf- fered saline (PBS) sections were incubated with a 1:500 dilution of biotin-SP-conjugated Affini Pure mouse antirat $\operatorname{IgG}(\mathrm{H} \& \mathrm{~L})$ (Jackson Immunoresearch, West Grove, PA). After rinsing with PBS, slides were incubated with 1:1000 dilution of peroxidase-conjugated streptavidin (Jackson Immunoresearch, West Grove, PA). Reaction sites were developed with a peroxidase substrate containing 3-amino-9-ethyl-carbazole and hydrogen peroxide substrate containing 3-amino-9-ethyl-carbazole and hydrogen peroxide in $0.1 \mathrm{M}$ sodium acetate buffer. The sections were fixed in $4 \%$ formalin, counterstained with Gill's \#3 haematoxylin, rinsed, and coverslipped with Vinol 205 (Air Products and Chemicals, Allentown, PA).

Experimental controls included tissue sections without the addition of the primary and secondary antibodies. Positive brown reactions on cell surfaces of two sections from each eye were counted in three representative highpower fields $(\times 400)$ with a $10 \mathrm{~mm} \times 10 \mathrm{~mm}$ grid. Cells in the cornea were counted in a masked fashion. The results were tabulated for each mouse strain.

\section{Delayed-Type Hypersensitivity (DTH) Responses}

Anti-asialo GM1-treated C.AL-20 mice and untreated control mice $(n=10)$ received no HSV-1 (negative controls), HSV-1 (KOS) in the cornea, or HSV-1 (KOS) subcutaneously (positive controls). DTH was assayed 5 days later as follows. Mice were challenged in the left hind footpad with $10^{8} \mathrm{PFU}$ ultraviolet (UV)-inactivated HSV-1 (KOS) in $50 \mu \mathrm{l}$ of medium using a 30 gauge needle on a Hamilton syringe (Reno, NV). The right footpad received an equal amount of uninfected supernate. Twenty-four hours later footpad swelling was measured using a Fowler micrometer (Schlesinger Tool, Brooklyn, NY) in a masked fashion. DTH was calculated as left footpad swelling minus right footpad swelling.

\section{Anti-HSV-1 Antibody Titres}

Blood was collected from the tail veins of each mouse and the samples for mice within a given experimental group were pooled on days 10 and 18 following corneal inoculation with HSV-1. Serial dilutions of serum samples were added to HSV-coated and control-coated 96-well plates (Whitaker Bioproducts, Walkersville, MD). An indirect ELISA technique ${ }^{9}$ was performed using a 1:2000 dilution of secondary $\mathrm{F}\left(\mathrm{ab}^{\prime}\right)_{2}$, rabbit anti-mouse $\mathrm{IgG}$ (heavy and light chains) peroxidase-conjugated antibody (Jackson Immunoresearch) and phenylenediamine dichloride substrate. Thirty minutes after the addition of substrate, the optical densities of all wells were measured by a Titertek Multiskan Spectrophotometer (Flow Labs, McLean, VA). Data are plotted as the absorbance at $492 \mathrm{~nm}$ against the serum dilution with the background of non-immune serum controls subtracted out as described previously. ${ }^{19}$ The endpoint of positive serum was defined as the reciprocal of the dilution which produced a mean absorbance of 0.2 above background in triplicate wells.

\section{Statistical Analysis}

Fisher's Protected LSD was used to analyse the incidence 
of stromal keratitis in different mouse strains on various observation days. The statistical significance of cytotoxicity experiments and immunohistological data was assessed by analysis of variance (ANOVA). Comparisons between specific means were made using Student's $t$-test.

\section{RESULTS}

\section{Stromal Keratitis in C57BL/6J-bj Mice}

To determine whether NK cells were essential in providing resistance to HSK in mice, we first compared the incidence and severity of HSK in normal C57BL/6J $(+/+)$ mice $(n=8)$, in $\mathrm{C} 57 \mathrm{BL} / 6 \mathrm{~J}$ mice carrying the $b g^{j} / b g^{j}$ (beige mutation) which renders them NK deficient $(n=7)$, and in Igh-1 disparate congenic mice of the BALB/c background (C.AL-20, $n=17$; BALB/c, $n=15$; and C.B-17, $n=20$ ). As is evident from Fig. 1, $\mathrm{C} 57 \mathrm{BL} / 6 \mathrm{~J}-\mathrm{bg}^{j}$ mice were just as highly resistant to HSK as were normal $\mathrm{C} 57 \mathrm{BL} / 6 \mathrm{~J}$ mice and both these strains were much more resistant to HSK compared with mice of BALB/c background $(p<0.0005)$. HSK was severe $(4+)$ in $89 \%$ of normal C.AL-20 mice and in 50\% of normal C.B-17 mice. All NK-depleted C.AL-20 and C.B-17 mice showed mild to moderate disease (1-2+).

The HSK resistance of the beige mice suggests that NK cells are not critical for the resistance to HSK seen in C57BL/6J mice. As previously described for the Igh-1 disparate congenics, ${ }^{2}$ C.AL-20 mice were highly susceptible to HSK, BALB/c mice had intermediate susceptibility while C.B-17 mice were most resistant $(p<0.0001)$.

\section{Effect of In Vivo Treatment with Anti-Asialo GMI on HSV-I Induced Stromal Keratitis}

We next performed NK depletion studies on both HSKsusceptible C.AL-20 $(n=22)$ and HSK-resistant C.B-17 mice $(n=21)$. Differences in susceptibility to HSK after corneal inoculation with HSV-1 were significant between NK-depleted and control mice of each strain, though the most striking effect of NK depletion was obvious in the HSK-susceptible C.AL-20 mice (Fig. 2). Treatment of mice with anti-asialo GM1 at the onset of corneal infection significantly reduced the incidence of stromal keratitis in C.AL-20 mice on all days $(p<0.005)$ and in C.B-17 mice on days 19 and $21(p<0.01)$. These results suggest that NK cells actually participate in HSK production.

\section{Effect of In Vivo Treatment with Anti-asialo GMI on In Vitro NK Activity and CTL Generation}

We examined the effect of in vivo NK depletion by antiasialo GM1 on CTL generation of spleen cells in response to in vitro stimulation with $\mathrm{HSV}-1$. At the termination of the clinical experiments, mice were killed; their splenocytes were then tested for NK activity against YAC-1 cell targets and for anti-HSV CTL activity using uninfected (3T3) and HSV-1-infected (HSV-3T3) BALB/c 3T3 fibroblasts. As previously reported, ${ }^{+}$C.AL-20 splenocytes showed significantly greater NK activity against YAC-1 and uninfected $3 \mathrm{~T} 3$ target cells than C.B-17 splenocytes $(p<0.01)$ (Table I). Intraperitoneal administration of antiasialo GM1 antibody was effective in almost completely abolishing spontaneous NK cytolytic activity in splenic lymphocytes from both mouse strains. Anti-HSV CTL activity (the difference in percentage specific lysis between HSV-infected and uninfected 3T3 targets) was equal among strains using the paired Student's $t$-test and was unaffected by in vivo treatment with anti-asialo GM1 antibody. These results indicate that the amelioration of HSK produced by anti-asialo GM1 antibody treatment does not derive from some unanticipated effect of such treatment on cytotoxic $\mathrm{T}$ cell activity.

\section{Anti-HSV-I Antibody Response after Treatment with Anti-asialo GMI}

We also measured the titres of anti-HSV-1 antibody produced in HSV-1-infected anti-asialo GMl-treated mice and compared them with titres in HSV-1-infected untreated mice. Fig. 3 indicates the mean net absorbance at $492 \mathrm{~nm}$ of the immune serum over the non-immune serum at each dilution. An absorbance or optical density (OD) of 0.2 was considered positive. Fig. 3 shows that the endpoint dilution producing an OD of 0.2 at 10 days postinfection was $<1: 25$ for untreated C.AL-20 and C.B-17 mice, 1:166 for C.B-17, and 1:118 for C.AL-20 anti-asialo GM1-treated mice. Eighteen days after infection the endpoint dilution producing an OD of 0.2 was $1: 1380$ and 1:668 for anti-asialo GM1-treated C.B-17 and C.AL-20 mice respectively, while serum from untreated C.B-17 and C.AL-20 mice had endpoints dilutions of 1:759 and 1:537 respectively. These results indicate that anti-asialo GM1 antibody treatment did not affect the production of antiHSV antibody at a time when keratitis would ordinarily be at its worst (day 18); such treatment did, however, result in an earlier appearance of anti-HSV antibody.

\section{Effect of Treatment with Anti-asialo GMI on Delayed Type Hypersensitivity Response}

In another series of experiments we tested the ability of HSV-1-infected C.AL-20 mice treated with anti-asialo GM1 to mount a DTH response to footpad injections with UV-inactivated HSV-1 $(n=10$ for each experimental group). The DTH response in normal and NK-depleted C.AL-20 mice was significantly depressed after corneal infection with HSV-1 $(p<0.001)$ compared with DTH responses to HSV after subcutaneous priming. Footpad swelling, however, was significantly less in NK-depleted

Table I. NK and CTL activity of anti-asialo GMI-treated and untreated Igh-l disparate congenic mice

\begin{tabular}{llrrr}
\hline & & \multicolumn{3}{c}{ Target cell } \\
\cline { 3 - 5 } Strain & Group & \multicolumn{1}{c}{ YAC-1 } & \multicolumn{1}{c}{3 3T3 } & HSV-3T3 \\
\hline C.AL-20 & Control & $39.8 \pm 5.9$ & $16.4 \pm 0.4$ & $72.8 \pm 7.7$ \\
& NK-depleted & $0.1 \pm 0.1$ & $1.3 \pm 0.8$ & $67.0 \pm 7.3$ \\
C.B-17 & Control & $13.1 \pm 3.9$ & $2.2 \pm 0.9$ & $68.6 \pm 7.9$ \\
& NK-depleted & $0.6 \pm 0.3$ & $3.6 \pm 0.6$ & $60.2 \pm 6.0$ \\
\hline
\end{tabular}

Values given mean percentage specific lysis from three experiments \pm standard error of the mean at an effector to target cell ratio of 50:1. 


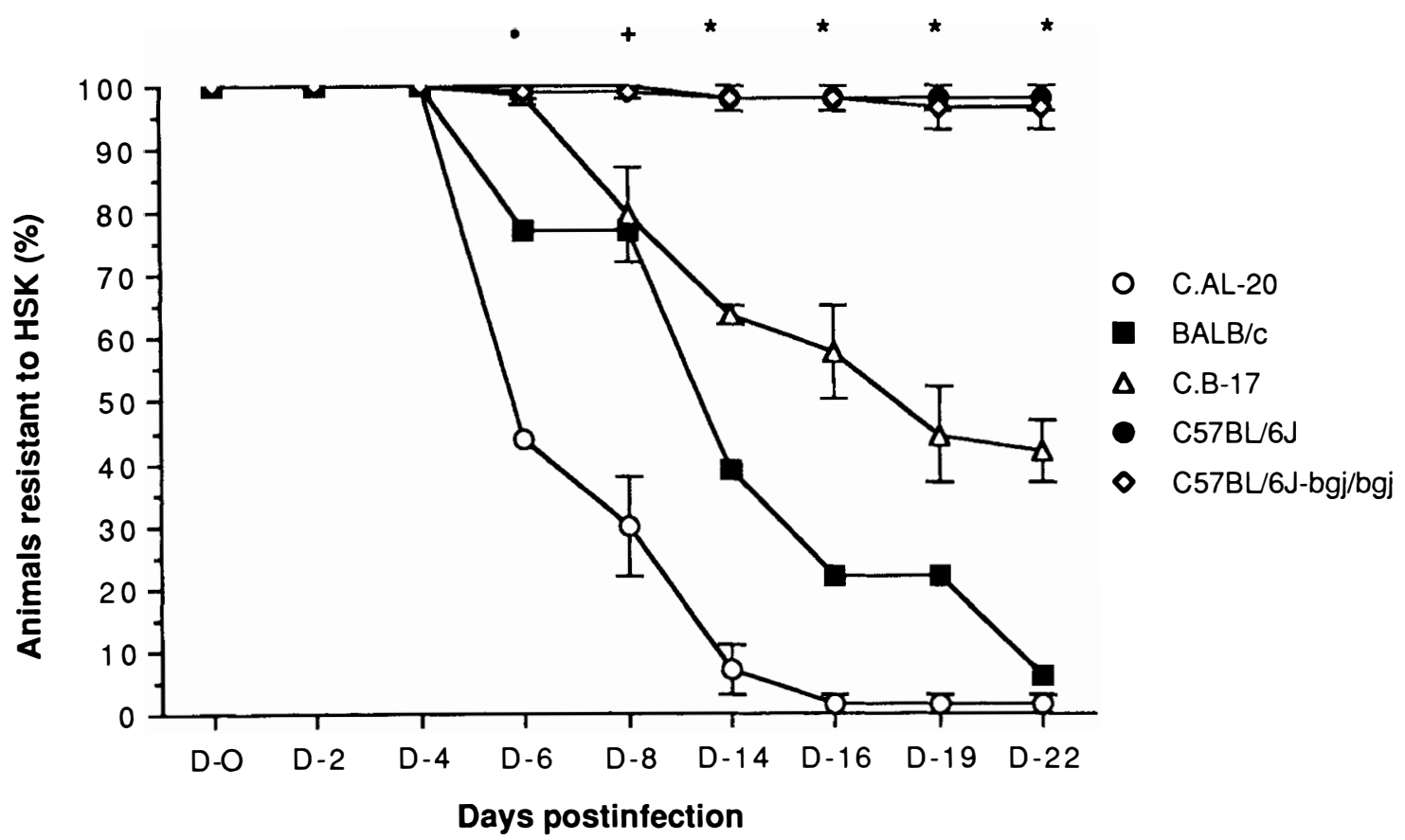

$\cdot=p<0.0001$ for $C . A L-20, B A L B / C ; N S$ for $C . B-17$

$+=p<0.05$

${ }^{*}=p<0.0005$

Fig. 1. Resistance from stromal keratitis plotted against observation interval in days following corneal inoculation with $2 \times 10^{+} P F U$ HSV-I KOS strain in BALB/C Igh-I disparate congenic mice and C57BL/6.J mice with and without the beige (bgj/bgj) mutation.

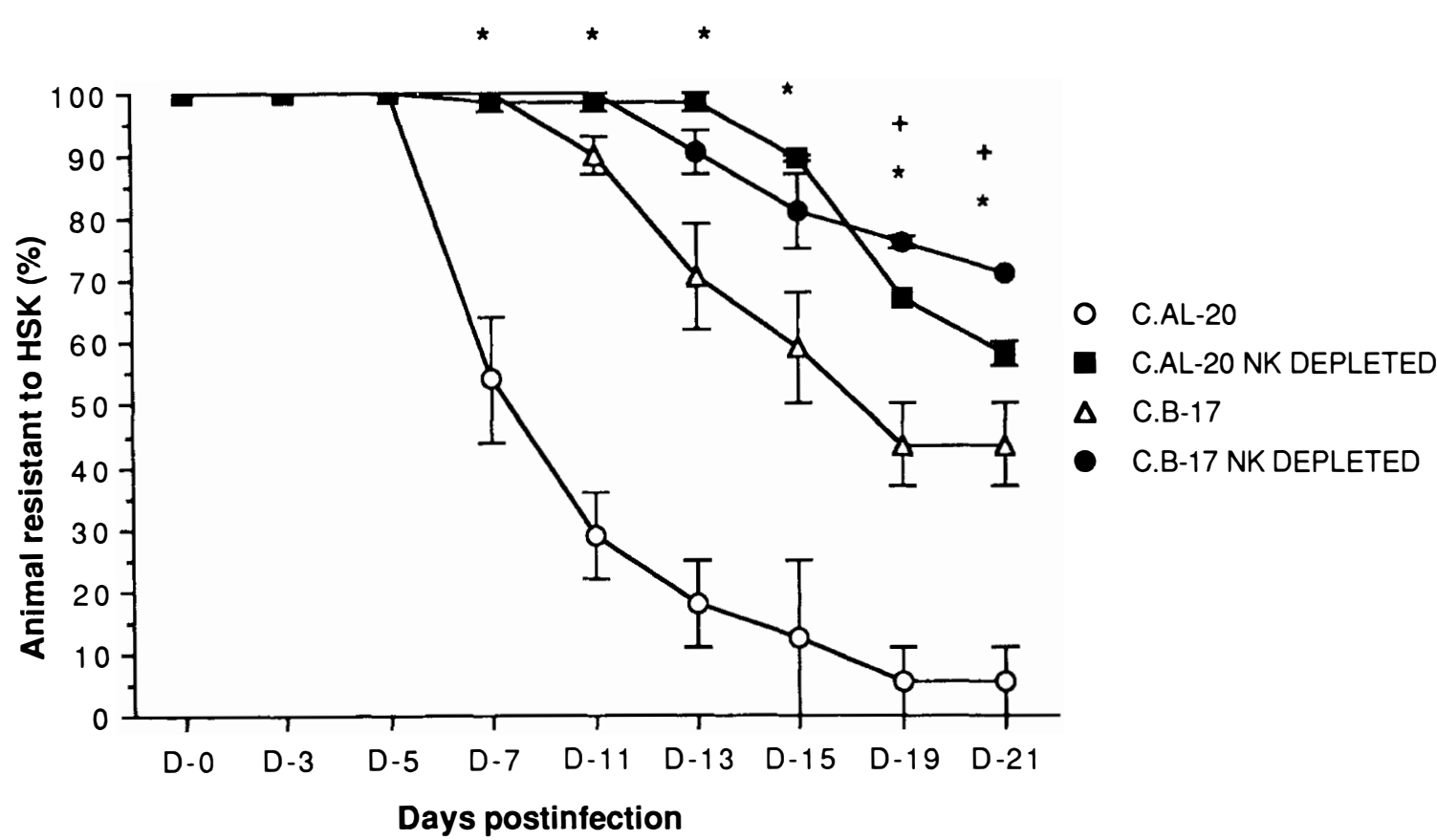

* $=$ significant difference between C.AL-20 and C.AL-20 NK depleted $(p<0.005)$

$+=$ significant difference between C.B-17 and C.B-17 NK depleted $(p<0.01)$

Fig. 2. Resistance from stromal keratitis plotted against observation interval in davs following corneal inoculation nith $2 \times 10^{+} P F U$ HSV-1 KOS strain in normal C.AL-20 and C.B-17 mice compared with anti-asialo GMI treated C.AL-20 and C.B-17 mice. 
animals compared with normal C.AL-20 mice after corneal and subcutaneous infection $(p \leqslant 0.02)$ (Table II).

\section{Immunopathology}

Infected corneas from untreated C.AL-20 mice showed significantly greater numbers of asialo GMl + and Thy 1.2 staining cells than infected corneas from untreated C.B-17 mice at all time points of analysis $(p<0.01)$; representative data are shown from day 21 (Table III). There were no significant differences seen between the two mouse strains in terms of the number of other cell types present in the cellular infiltrate in infected corneas. Intraperitoneal injections of anti-asialo GMI antibody significantly reduced the number of asialo-GM1+ cells in C.AL-20 infected corneas as compared with infected corneas from untreated C.AL-20 mice $(p<0.0001)$. There was virtually no effect of anti-asialo GM1 antibody treatment on the already paltry numbers of NK cells present in infected C.B-17 corneas. Anti-asialo GM1 antibody treatment had no significant effect on the number of other cell types, e.g. macrophages, $\mathrm{Ia}^{+}$cells, $\mathrm{T}$ cells and their L3T4 and Lyt- 2 subsets, present in infected corneas of either strain.

\section{DISCUSSION}

The damage to the cornea in HSK results principally from an immunological response to virus or viral antigens. The exact mechanisms of the presumed immunopathology, however, remain to be resolved. Several investigators have claimed that $\mathrm{T}$ lymphocytes are essential mediators of the disease. ${ }^{20}{ }^{25}$ Evidence for a DTH response triggered by CD4+ T lymphocytes has been presented. ${ }^{20}$ Less clear, however, is the role of CD8+ T lymphocytes, which have been reported to be the primary mediators of HSK. ${ }^{26.27}$ On the other hand, other investigators have demonstrated that CD8+ $\mathrm{T}$ cells downregulate the immune response in HSK, ${ }^{25.28}$ and our work tends to corroborate the validity of the latter conclusion. ${ }^{3}$

In contrast, few reports have examined the role of $\mathrm{NK}$

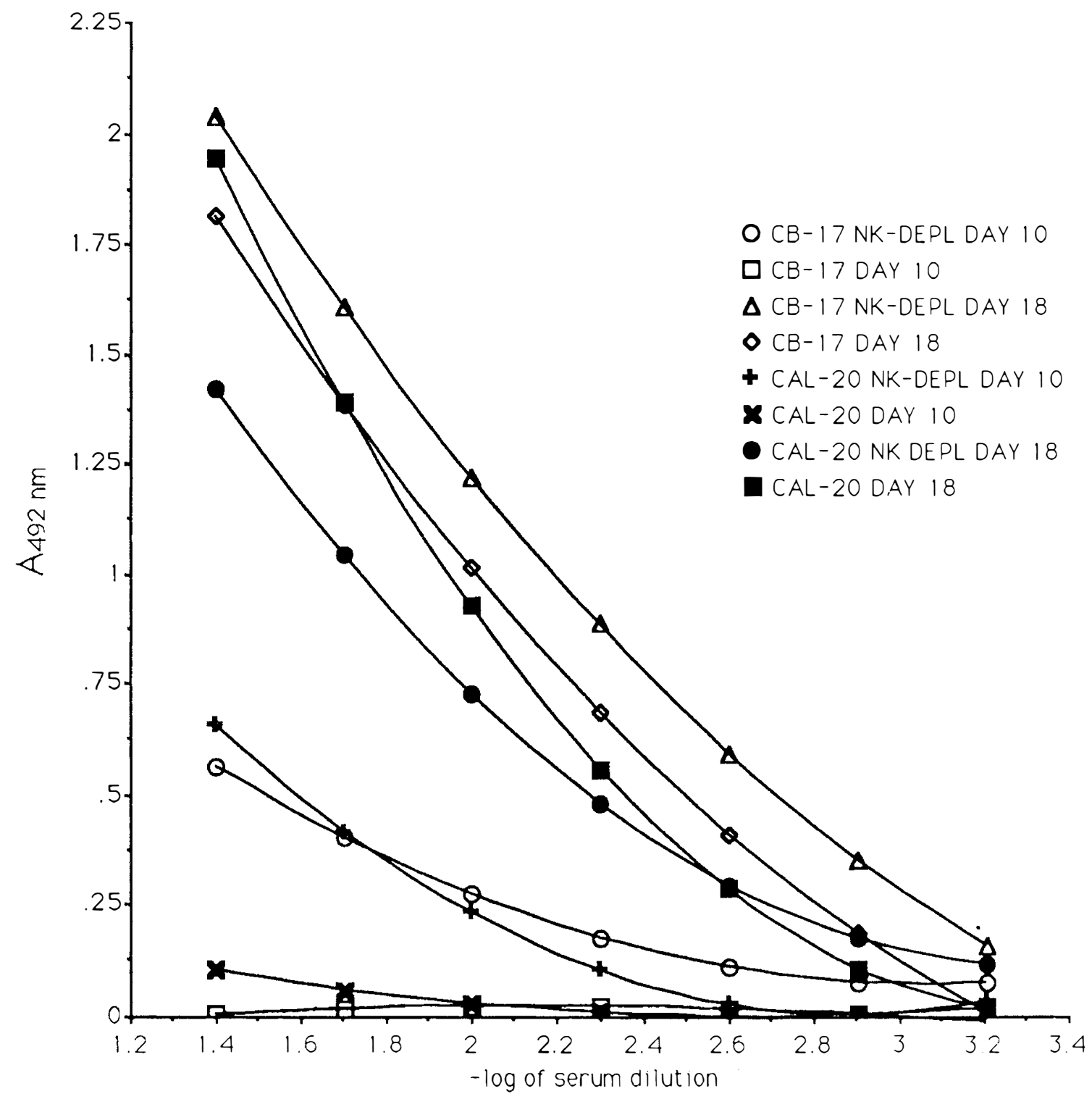

Fig. 3. ELISA titration curve indicating the mean net absorbance at 492 nm of the immune serum minus the non-immune serum at each dilution. An absorbance or optical density $(O D)$ of 0.2 was considered positive. 
Table II. Delayed type hypersensitivity response to footpad injection with HSV-1 in C.AL-20 mice

\begin{tabular}{llc}
\hline $\begin{array}{l}\text { Route of infection } \\
\text { with HSV-1 }\end{array}$ & NK depletion & $\begin{array}{c}\text { Mean change in } \\
\text { footpad thickness }\end{array}$ \\
\hline No HSV-1 & No & 1.2 \\
No HSV-1 & Yes & 2.6 \\
Cornea & No & $20.4^{*}$ \\
Cornea & Yes & $5.7^{*}$ \\
Subcutaneous & No & $48.4^{*}$ \\
Subcutaneous & Yes & $21.6^{*}$ \\
\hline
\end{tabular}

*Significantly different $(p \leqslant 0.02)$.

cells in the development of HSK. There is substantial evidence that non-specific host defences active during the first few days of virus infection, such as the activation of NK cells and the induction of interferon (IFN), have a pronounced influence on the outcome of infection. ${ }^{14,29.30} \mathrm{NK}$ cells are known to play an important role in lysing malignant cells and virus-infected cells in the body. ${ }^{31}{ }^{32}$ Unlike CTL, which bind targets by a dual recognition mechanism involving both specific $\mathrm{T}$ cell receptors (TCRs) and the major histocompatibility complex (MHC), NK cells do not have TCRs and are not MHC-restricted. ${ }^{33.34}$ In considering a possible role for NK cells in preventing HSK, the question of whether in vitro assays of NK activity in murine splenic lymphocytes reflected the activity of lymphocytes at the site of infection was raised. Previous observations made in our laboratory indicated that splenic lymphocytes from HSK-susceptible C.AL-20 mice had significantly higher NK activity than that of HSK-resistant C.B-17 mice after intraperitoneal infection. ${ }^{4}$ Brandt and coworkers reported increased splenic NK activity in $\mathrm{BALB} / \mathrm{c}$ mice following corneal HSV-1 infection, and this could be abrogated by antibodies to IFN $\alpha, \beta$ and $\gamma$. Despite the induction of high levels of NK activity, mice developed severe ocular disease or died of encephalitis. ${ }^{35}$ A close correlation has been shown between resistance to intraperitoneal infections with $\mathrm{HSV}-1$ in $\mathrm{C} 57 \mathrm{BL} / 6 \mathrm{~J}$ mice and the production of HSV-induced IFN. ${ }^{36}$ No significant differences in the early IFN levels, however, were found among susceptible and resistant mice with BALB/c background. ${ }^{4}$ Furthermore, we have been unable to detect differences in IFN level after HSV-1 ocular infection in the Igh-1 disparate BALB/c congenic mice (data not shown). Therefore, resistance to HSK can not be attributed solely to the antiviral effects of IFN.

Peripheral blood lymphocytes (PBL) isolated from patients with recurrent herpetic corneal infections exhibited markedly enhanced NK lytic activity against both HSV-infected and uninfected cell targets compared with PBLs from controls with no recollection of herpetic recurrences. IFN was produced equally by HSV-1-stimulated PBL with high lytic activity (from patients) and very low lytic activity (from controls) ${ }^{37}$ If HSV stimulation of non-specific cytotoxic activity and loss of the capacity to discriminate HSV-1-infected from uninfected cells led to a necrotising attack at sites of viral shedding, herpetic lesions could therefore represent necrosis via immunopathological mechanisms.
Table III. Cell subpopulations in HSV-1-infected corneas taken 21 days post-infection

\begin{tabular}{|c|c|c|c|c|}
\hline \multirow[b]{2}{*}{ Cell marker } & \multicolumn{2}{|c|}{ C.AL-20 } & \multicolumn{2}{|c|}{ C.B-17 } \\
\hline & Control & NK-depleted & Control & NK-depleted \\
\hline Thy 1.2 & $66.8 \pm 12.3$ & $41.0 \pm 13.6$ & $19.5 \pm 16.9$ & $43.4 \pm 13.1$ \\
\hline L3T4 & $11.9 \pm 2.9$ & $13.6 \pm 3.3$ & $13.5 \pm 4.4$ & $16.1 \pm 3.1$ \\
\hline Lyt-2 & $5.5 \pm 2.2$ & $7.1 \pm 2.4$ & $1.5 \pm 3.1$ & $6.4 \pm 2.0$ \\
\hline Ia & $26.1 \pm 4.9$ & $18.2 \pm 5.4$ & $14.2 \pm 5.5$ & $12.8 \pm 5.2$ \\
\hline Mac & $39.2 \pm 8.3$ & $23.2 \pm 9.0$ & $14.2 \pm 10.0$ & $32.5 \pm 10.0$ \\
\hline Asialo GM1 & $15.0 \pm 2.4$ & $0.0 \pm 0.5$ & $0.5 \pm 0.5$ & $0.5 \pm 0.5$ \\
\hline
\end{tabular}

Values represent mean cell counts from three high-power fields $(\times 400)$ \pm standard error. Six mice were counted in each group.

To examine this question, we used antibody to render mice NK deficient in our study. Anti-asialo GM1 antibody has been shown to eliminate NK activity effectively in cells of various strains of mice and rats in vivo. ${ }^{12}$ The specificity of anti-asialo GM1 antibody for NK cells is high but not absolute. Asialo GM1, a glycosphingolipid, is detectable on T cells and monocytes. ${ }^{38-40}$ There is no evidence, however, that anti-asialo GM1 treatment interferes with the in vivo function of macrophages. ${ }^{10.41}$ Its effect on cytotoxic $\mathrm{T}$ and natural cytotoxic cell function also appears to be minimal. ${ }^{12.41 .42}$ Our data show no significant effect of in vivo anti-asialo GM1 treatment on CTL activity. Our re;ults from in vivo NK depletion experiments suggest that NK cells are necessary for the development of HSK since their depletion at the onset of corneal infection ameliorates its severity. We found no support for the contention that NK cells were essential in providing resistance to the development of HSK in mice. Neither NK-deficient $\mathrm{C} 57 \mathrm{BL} / 6 \mathrm{~J}$ mice carrying the beige mutation nor HSK-resistant C.B-17 mice given anti-asialo GM1 antibody showed an increased susceptibility to developing stromal keratitis. In fact, anti-asialo GM1-treated C.B-17 mice showed a further decrease in susceptibility to HSK.

Although the mechanism by which NK cells promote the expression of HSK in the murine model is unclear, our data suggest that HSK may represent an immune reaction in which NK cells, possibly stimulated by antigen-specific CD4+ T cells, launch a necrotising cytolytic attack on both HSV-infected and bystander uninfected cells at the site of viral shedding.

Some reports suggest that, in the effector phase of DTH caused by tumour antigens, keyhole limpet haemocyanin or ovalbumin, non-specific killer cells of NK linkage are induced by the reaction. ${ }^{43.44}$ This could conceivably explain why DTH responses were depressed in NKdepleted mice infected with HSV-1 in our experiments.

NK cells proliferate in response to interleukin 2 (IL-2) secreted by CD4+ T lymphocytes and result in the induction of lymphokine activated killer (LAK) activity. ${ }^{44-47}$ LAK cells induced by IL-2 are potent cytotoxic cells that may conceivably mediate at least part of the immunopathology in HSK. In vivo depletion of NK cells with antiasialo GM1 would, in this setting, be expected to limit the necrosis produced via immunopathological mechanisms. While NK cells with anti-asialo GM1 would, in this setting, be expected to limit the necrosis produced via immu- 
nopathological mechanisms. While NK cells were not the predominant cell type in the inflammatory cellular infiltrate of infected corneas in our experiments, their presence seems to be required in the initial stages of stromal keratitis.

An alternative explanation could lie in the hypothesis that normal NK cells may have a role in regulating physiological immune responses. NK cells have been shown experimentally to suppress antibody responses in B cells to both mitogenic and antigenic stimuli ${ }^{48-53}$ Preliminary data in our laboratory suggest that in vivo depletion of $\mathrm{B}$ cells and suppression of the HSV-specific antibody response results in an increased incidence of HSK in previously HSK-resistant mice (manuscript in preparation). Mice passively immunised with anti-HSV-1 antibody show increased resistance to HSV-1 infections. ${ }^{54,55}$ Other investigators have observed that in vitro or in vivo depletion of murine NK cells results in an increase in antigen or mitogen-induced antibody production..$^{51.53,56-58} \mathrm{We}$ detected an increase in early anti-HSV antibody titres in anti-asialo GM1-treated mice as compared with untreated mice. An augmentation of the HSV-specific humoral response following NK cell depletion could conceivably contribute to the increased resistance to HSK seen in antiasialo GM1-treated mice.

In conclusion, treatment of mice with anti-asialo GM1 antibody abolished the NK activity of these mice and decreased the incidence of HSK in mice corneally infected with HSV-1. C57BL/6J mice carrying the beige mutation, which impairs their NK activity, showed no increased susceptibility to HSK as compared with normal NK-competent $\mathrm{C} 57 / \mathrm{BL} / 6 \mathrm{~J}$ mice. These results indicate that NK cells are participants in the development of herpetic stromal keratitis in the murine model and do not have a prominent protective role in this disease.

Supported by NIH grant EY-06008 and by the Deutsche Forschungsgemeinschaft (ME 1104-1/1).

Key words: Anti-asialo GM1 antibody, Herpes simplex virus type 1, Igh-I, Keratitis, Natural killer cells.

\section{REFERENCES}

1. Foster CS, Tsai Y, Monroe JG, Campbell R, Wetzig R, Knipe D, Greene MI. Genetic studies on murine susceptibility to herpes simplex keratitis. Clin Immunol Immunopathol 1986;40:313-25.

2. Opremcak EM, Wells PA, Thompson P, Daigle JA, Rice BA, Millin J, Foster CS. Immunogenetic influence of Igh-1 phenotype on experimental herpes simplex virus type -1 corneal infection. Invest Ophthalmol Vis Sci 1988;29:749-54.

3. Opremcak EM, Rice BA, Wells PA, Foster CS. Histology and immunohistology of Igh-1 restricted herpes simplex keratitis in BALB/c congenic mice. Invest Ophthalmol Vis Sci 1990;31:305-12.

4. Tamesis RR, Foster CS. Natural killer cellular cytotoxicity against herpes simplex virus-infected cells in Igh-1 disparate mice. Invest Ophthalmol Vis Sci 1990;31:2224-8.

5. Foster CS. Herpes simplex virus-induced destructive corneal disease. Eye 1989;3:194-203.

6. Whittum JA, Niederkorn JY, McCulley JP, Streilein JW. Intracameral inoculation of herpes simplex virus type 1 induces anterior chamber associated immune deviation. Curr Eye Res 1983;2:691-7.
7. Streilein JW. Immune regulation and the eye: a dangerous compromise. FASEB J 1987;1:199-208.

8. Benson JL, Niederkorn JY. In situ suppression of delayedtype hypersensitivity: another mechanism for sustaining the immune privilege of the anterior chamber. Immunology 1991;74:153-9.

9. Bancroft GJ, Shellam GR, Chalmer JE. Genetic influences on the augmentation of natural killer cells during murine cytomegalovirus infection: correlation with patterns of resistance. J Immunol 1981;126:988-94.

10. Stein-Streilein J, Guffee J. In vivo treatment of mice and hamsters with antibodies to asialo GM1 increases morbidity and mortality to pulmonary influenza infection. J Immunol 1986;136:1435-41.

11. Rager-Zisman B, Quan PC, Rosner M, Moller JR, Bloom $\mathrm{BR}$. Role of NK cells in protection of mice against herpes simplex virus -1 infection. J Immunol 1987;138:884-8.

12. Habu S, Fukui H, Shimamura M, Kasai M, Nagai Y, Okamura K, Tamaoki N. In vivo effects of anti-asialo GM1. I. Reduction of NK activity and enhancement of transplanted tumour growth in male mice. J Immunol 1981;127:34-8.

13. Habu S, Akamatsu K, Tamaoki N, Okumura K. In vivo significance of NK cell on resistance against virus (HSV-1) infections in mice. J Immunol 1984;133:2743-7.

14. Welsh RM. Mouse natural killer cells: induction, specificity, and function. J Immunol 1978;121:1631-5.

15. Roder JC. The beige mutation in the mouse. I. A stem cell predetermined impairment in natural killer cell function. $\mathrm{J}$ Immunol 1979;123:2163-73.

16. Brenan M, Parish CR. Automated fluorometric assay for T cell cytotoxicity. J Immunol Methods 1988;112:121-30.

17. Yap KL, Ada GL. Cytotoxic T cells specific for influenza virus-infected target cells. Immunology 1977;32:151-9.

18. Nakamura RM, Voller A, Bidwell DE. Enzyme immunoassays: heterogeneous and homogeneous systems. In: Weir DM, editor. Handbook of experimental immunology. Oxford: BS Publications, 1986:27.1-27.20.

19. McKendall RR, Woo W. Antibody activity to herpes simplex virus in mouse Ig classes and IgG subclasses. Arch Virol 1988;98:225-33.

20. Easty DL, Mairi RN, Jones BR. Cellular immunity in herpes simplex keratitis. Trans Ophthalmol Soc UK 1973;93: 171-80.

21. Lausch RN, Kleinschradt WR, Monteiro C, Kayes SB, Oakes JE. Resolution of HSV corneal infection in the absence of delayed-type hypersensitivity. Invest Ophthalmol Vis Sci 1985;26:1509-15.

22. Metcalf JF, Hamilton DS, Reichert RW. Herpetic keratitis in athymic (nude) mice. Infect Immunol 1979;26:1164-71.

23. Chandler JW. Immunological mechanisms involved in viral ocular design. Ophthalmology 1980;87:1239-43.

24. Russell RG, Nasisse MP, Larson HS, Rouse BT. Role of T lymphocytes in the pathogenicity of herpetic stromal keratitis. Invest Ophthalmol Vis Sci 1984;25:938-44.

25. Newell CK, Martin S, Sendele D, Mercadal CM, Rouse BT. Herpes simplex virus-induced stromal keratitis: role of T-lymphocyte subsets in immunopathology. J Virol 1989;63:769-75.

26. Hendricks RL, Epstein RJ, Tumpey T. The effect of cellular immune tolerance to HSV-1 antigens on immunopathology of HSV-1 keratitis. Invest Ophthalmol Vis Sci 1989;30: 105-15.

27. Hendricks RL, Tao MSP, Glorioso JL. Alterations in the antigenic structure of two major HSV-1 glycoproteins, gC and $\mathrm{gB}$, influence immune regulation and susceptibility to murine herpes keratitis. J Immunol 1989; 142:263-9.

28. Newell CK, Sendele D, Rouse BT. Effects of CD4+ and CD8+ T-lymphocyte depletion on the induction and expression of herpes simplex stromal keratitis. Reg Immunol 1989;2:366-9. 
29. Welsh RM. Hallenback LA. Effect of virus infections on target cell susceptibility to natural killer cell-mediated lysis. J Immunol 1980;124:2491-7.

30. Welsh RM. Regulation of virus infections by natural killer cells. Nat Immun Cell Growth Regul 1986;5:169-99.

31. Trichieri G, Perussia B. Human natural killer cells: biologic and pathologic aspects. Lab Invest 1984;50:489-513.

32. Lopez C. Resistance to herpes simplex virus type I (HSV-1). In: Haller $\mathrm{O}$, editor. Natural resistance to tumours and viruses: current topics in microbiology and immunology 92. New York: Springer, 1981:15-24.

33. Herberman RB, Reynolds CW, Ortaldo JR. Mechanism of cytotoxicity by natural killer cells. Annu Rev Immunol 1986;8:651-80.

34. Goldfarb RH. Cell-mediated cytotoxic reactions. Hum Pathol 1986; 17:138-45.

35. Brandt CR, Salkowski CA. Activation of NK cells in mice following corneal infection with herpes simplex virus type-1. Invest Ophthalmol Vis Sci 1992:33:113-20.

36. Zawatzky R, Gresser I, DeMaeyer E, Kirchner H. The role of interferon in the resistance of $\mathrm{C} 57 \mathrm{BL} / 6$ mice to various doses of herpes simplex virus type 1. J Infect Dis 1982;146:405-10.

37. Hendricks RL, Sugar J. Lysis of herpes simplex virus (HSV) infected targets. III. Effects of HSV on natural killer activity. Invest Ophthalmol Vis Sci 1985;26:201-7.

38. Akagawa KS, Maruyama Y, Takano M, Kasai M, Tokunaga T. A cell surface antigen expressed on mouse lung macrophages. Microbiol Immunol 1982;25:1215-20.

39. Kasai M, Iwamori M, Nagai Y, Okamura K. Tada T. A glycolipid on the surface of mouse natural killer cells. Eur J Immunol 1980;10:175-80.

40. Yang H, Yogeeswaran G, Bukowski JF. Expression of asialo GM1 and other antigens and glycolipids on NK cells and spleen leukocytes in virus-infected mice. Nat Immun Cell Growth Regul 1985;4:21-39.

41. Kawase ID, Urdel L, Brooks CG, Henney CS. Selective depletion of NK cell activity in vivo and its effects on the growth of NK-sensitive and NK-resistant tumour cell variants. Int J Cancer 1982;29:567-74.

42. Kasai M. Yoneda T, Habu S, Maruyama Y, Okumura K. Tokunaga K. In vivo effect of anti-asialo GMl antibody on natural killer cell activity. Nature 1981:291:334-5.

43. Takao T, Morikawa Y. Kuribayashi K. Saito K. Induction of nonspecific killer cells by delayed-type hypersensitivity against soluble protein antigens in murine peritoneal cavities. Cancer Immunol Immunother 1989:29:219-25.

44. Toko T, Fujimoto S. Augmentation of anti-tumour immunity in low-responder mice by various biological responder modifiers: analysis of effector mechanism. Jpn J Cancer Res 1989:80:1212-9.

45. Lotze MT, Grimm EA, Mazumder A, Strausser JL, Rosen- berg SA. In vitro growth of cytotoxic human lymphocytes. IV. Lysis of fresh and cultured autologous tumour by lymphocytes cultured in $\mathrm{T}$ cell growth factor (TCGF). Cancer Res 1981;41:4420-5.

46. Grimm EA, Mazumder A, Zhang HZ, Rosenberg SA. Lymphokine-activated killer cell phenomenon: lysis of natural killer-resistant fresh solid tumour cells by interleukin- 2 activated autologous human peripheral blood lymphocytes. J Exp Med 1982:155:1823-41.

47. Williams JM, Abbud-Filho M, Kelley VE, Strom TB. Interleukin-2 apparently upregulates its receptor and induces proliferation of various resting mononuclear leukocytes in the absence of antigen. Cell Immunol 1985;94:383-93.

48. Nabel G, Allard WJ, Cantor H. A cloned cell line mediating natural killer cell function inhibits immunoglobulin secretion. J Exp Med 1982;156:658-63.

49. Tilden AB. Abo T, Balch CM. Suppression cell function of human granular leukocytes identified by the HNK (Leu-7) monoclonal antibody. J Immunol, 1983:130:1171-5.

50. Arai S, Yamamoto H, Itoh K. Kumagai K. Suppressive effect of human natural killer cells on pokeweed mitogeninduced B cell differentiation. J Immunol 1983;131:651-7.

51. Abruzzo LV. Rowley DA. Homeostasis of the antibody response: immunoregulation by $\mathrm{NK}$ cells. Science 1983;222:581-5.

52. Robles CP, Pollack SB. Regulation of the secondary in vitro antibody response by endogenous natural killer cells: kinetics, isotype preference, and non-identity with $\mathrm{T}$ suppressor cells. J Immunol 1986:137:2418-24.

53. Robles CP, Pollack SB. Asialo-GMl+ natural killer cells directly suppress antibody-producing B cells. Nat Immuno Cell Growth Regul 1989:8:209-22.

54. Raizman MB. Foster CS. Passive transfer of anti-HSV-1 IgG protects against stromal keratitis in mice. Curr Eye Res 1988:7:823-9.

55. Balachandran N, Bacchetti S, Rawls WE. Protection against lethal challenge of $\mathrm{BALB} / \mathrm{c}$ mice by passive transfer of monoclonal antibodies to five glycoproteins of herpes simplex virus type 2. Infect Immunol 1982;37:1132-7.

56. Suzuki S, Suzuki R, Onta T, Kumagai K. Suppression of B-cell differentiation by natural killer (asialo $\mathrm{GM} 1+$ ) cells in mice. Nat Immunol Cell Growth Regul 1986:5:75-89.

57. Khater M, Macai J, Genyea C, Kaplan J. Natural killer cell regulation of age-related and type specific variations in antibody response to pneumococcal polysaccharides. J Exp Med 1986;164:1505-15.

58. Mason PD, Weetman AP, Sissons JGP, Borysiewicz LK. Suppressive role of NK cells in pokeweed mitogen-induced immunoglobulin synthesis: effect of depletion/enrichment of Leu 11 b+ cells. Immunology 1988;65:113-8. 